\title{
EL ESTUDIO DE LA ORINA. LUIS CIFUENTES DELATTE EN EL PASO DEL ARTE A LA CIENCIA
}

\author{
Jesús Salinas Casado
}

Servicio de Urología. Hospital Clínico. Universidad Complutense. Madrid. España.

Resumen.- OBJETIVO: Destacar la importancia del estudio de la orina así como la figura insustituible de Luis Cifuentes Delatte.

MÉTODOS: Se revisa la diferente metodología de estudio de la orina.

RESULTADOS: El estudio de la orina sigue teniendo gran importancia diagnóstica como demostró Luis Cifuentes Delatte, aunque haya sufrido en la actualidad inevitables modificaciones, debido fundamentalmente al avance tecnológico y la demanda social. \begin{tabular}{l|}
$\frac{0}{u}$ \\
$\frac{0}{0}$ \\
$\frac{0}{0}$ \\
$\frac{0}{0}$ \\
$\frac{a}{0}$ \\
0 \\
0 \\
0 \\
0
\end{tabular}

Jesús Salinas Casado Solano, 6 - 4 D 28223 Prado de Somosaguas Madrid. (España).

jsalinascasado@yahoo.es
CONCLUSIONES: No hay que olvidar nunca en la práctica clínica un análisis del sedimento urinario,como defendió en su día el profesor Luis Cifuentes Delatte.

Palabras clave: Sedimento urinario. Microscopía. Luis Cifuentes Delatte.

Summary.- OBJECTIVE: To emphasize the importance of the study of urine samples as well as the non replaceable figure of Dr. Luis Cifuentes Delatte.

METHODS: We review the methodology of the study of urine samples.

RESULTS: Urine analysis keeps a great diagnostic importance as Dr. Luis Cifuentes Delatte demonstrated, although it unavoidably has suffered modifications due to technological development and social needs.

CONCLUSIONS: We should never forget in our clinical practice urine analysis of the sediment, as Dr. Luis Cifuentes Delatte supported in his time.

Keywords: Urine sediment. Microscopy. Dr. Luis Cifuentes Delatte. 


\section{INTRODUCCIÓN}

El arte de basar un diagnóstico y pronóstico en el examen macroscópico de la orina (Uroscopia), representó un papel muy importante en la medicina del pasado.

Hipócrates la utilizó con discreción y sentido común, pero en las manos de los últimos médicos griegos y de la edad media, su práctica se convirtió en una pseudociencia compleja, con un diagnóstico basado fundamentalmente en la fantasía y alquimia.

Durante el renacimiento este método, fue desacreditado y recusado por Paracelso. La alquimia inició su lenta transformación, y se introdujo el análisis químico de la orina. Pero no es hasta la edad moderna, cuando el examen químico y microscópico de la orina, convirtió el arte en ciencia.

Esto es, fue necesario el desarrollo de diversas técnicas químicas, y sobretodo microscópicas, para dar el carácter científico al estudio del sedimento urinario.

\section{MUESTRA DE ORINA}

Antes de la observación microscópica del sedimento urinario, es muy importante la obtención de la muestra. En este primer paso para el examen de orina, existen riesgos que pueden invalidar todos los hallazgos posteriores, puesto que a menos que se observen reglas estrictas de preparación, y se ponga un cuidado extremo en su recogida, la muestra de orina será inservible, o peor aún, inducirá a errores. Para minimizar los riesgos de contaminación por bacterias y sustancias extrañas, la orina deberá emitirse directamente en el interior de un recipiente estéril y desechable.

El paciente masculino, primero se limpiará por completo el glande y se recogerá la última porción del chorro urinario. En la mujer, se deberá evitar, siempre que sea posible la cateterización, ya que las instrumentaciones, introducen con frecuencia bacterias en el interior del tracto urinario. La recogida se puede realizar colocando a la paciente en posición de litotomía, limpiando cuidadosamente los genitales externos, y recogiendo la muestra de la porción media de la micción. A continuación, se somete la muestra de orina (diez mililitros), a centrifugación durante sesenta segundos, a unas 1500 revoluciones por minuto. De esta forma, en el fondo del tubo, se obtiene un sedimento, donde se depositan los elementos formes a estudio. Una gota de este sedimen- to, se deposita en un porta, sobre el que se coloca un cubre antes de proceder al estudio microscópico.

Lo ideal sería examinar la orina dentro de la hora siguiente a la emisión. Bajo ninguna circunstancia se debe utilizar una muestra transcurridas 24 horas.

\section{1) TÉCNICAS MICROSCÓPICAS}

\section{Microscopía óptica normal}

El contraste óptico de los elementos de un sedimento es muy pequeño en el microscopio óptico, que por otra parte sería adecuado para la observación de preparaciones fijadas y coloreadas. Para los sedimentos, la iluminación habitual de estos microscopios no es la más conveniente. Para alcanzar una mejor definición y contraste es aconsejable descender el condensador.

La utilización de filtros de color, colocados debajo del condensador, pueden ayudar al poner de relieve los detalles de estructuras presentes en el sedimento, sin necesidad de tinción. El filtro debe ser de un color complementario con el del elemento que se desea acentuar. Para estructuras azules se utilizará un filtro amarillo, para estructuras rojas, un filtro verde; para una preparación con una tinción corriente, el mejor filtro es el amarillo ácido pícrico o gris amarillento. Para suprimir los objetos fuertemente teñidos - para resaltar aun más, detalles internos, se debe utilizar un filtro del mismo color.

\section{Microscopía de contraste de fases}

La peculiaridad de esta técnica es que amplifica y hace perceptibles los débiles contrastes entre las diferentes microestructuras celulares del sedimento urinario, sin necesidad de tinciones. El microscopio de contraste de fases matiza los tonos del gris claro al muy oscuro.

Este método incluye el uso de un condensador y un objetivo especial para aumentar el contraste y mejorar la visibilidad y definición de aquellas estructuras con un índice de refracción similar al del medio que le rodea.

El microscopio de contraste de fases, al retrasar artificialmente, en un cuarto de longitud de onda, la luz difractada, produce (a través de su transformación en diferencias de amplitud) un halo en el lugar de contacto de superficies con índices de refracción ligeramente distintos. Esto da lugar a un refuerzo de la imagen y distintos matices de claro-oscuro. Esta 
técnica permite no sólo la identificación de los diferentes elementos formes de la orina (capacidad cualitativa), sino una cuantificación aproximada de dichos elementos por campo microscópico. En la Figura 1 puede observarse una leucocituria, de mediana intensidad.

\section{Microscopía de interferencia diferencial}

Esta técnica favorece la visualización y el examen del material vivo sin teñir, al proporcionar al objeto una aparente tridimensionalidad. Ello permite al observador ver la forma geométrica, más que la diferencia de contraste. Debido a este factor espacial y a la "resolución vertical", permite una identificación más fácil de objetos diminutos. También favorece el contraste de colores.

\section{Microscopía con luz polarizada}

La inclusión de dos cristales polaroides (polarizador y analizador) convierten al microscopio corriente de campo claro en un microscopio polarizante. Este método de iluminación resulta especialmente válido para la identificación de sustancias anisotrópicas (de doble refracción), como los cuerpos grasos ovales en la orina. Asimismo, esta técnica permitiría realizar un diagnóstico diferencial correcto entre ciertos cristales (oxalato calcico monohidrato) y los hematies del sedimento de orina. Los hematies no son visibles con los polaroides cruzados, mientras que sobre el fondo oscuro, los cristales destacan intensamente por su policromía (Figura 2).

\section{Microscopía electrónica de transmisión (TEM).}

Esta técnica recuerda a un proyector de diapositivas. Un proyector emite un rayo de luz, que atraviesa una diapositiva, siendo la luz afectada por el contenido de la diapositiva. Aquellos efectos resultan en que sólo ciertas partes del rayo de luz son transmitidas a través de ciertas partes de la diapositi$\mathrm{va}$, siendo proyectado en una pantalla formando una imagen aumentada de la diapositiva.

Pues bien, el TEM es similar excepto que en vez del rayo de luz, es un haz de electrones, que atraviesa la muestra en sustitución de la diapositiva.

El TEM, posee un cañón de electrones, que produce una corriente de electrones monocromáticos, que mediante un sistema de lentes y condensadores, choca con la muestra, siendo transmitidos parte de ellos. Una lente objetivo la convierte en imagen, que es proyectada sobre una pantalla de fósforo, para que el usuario pueda verla.

Las imágenes oscuras de la imagen representan las muestras que menos electrones fueron transmitidos a su través (mayor grosor o densidad), mientras que las áreas claras de la imagen corresponden a las muestras que más electrones fueron transmitidos a su través (menor grosor o densidad).

Una de las aplicaciones del TEM al estudio microscópico del sedimento urinario sería la observación de la morfología de los hematíes. En este sentido, los hematies conservarían su forma característica bicóncava (isomórficos) cuando procediera del tracto urinario inferior (Figura 3) mientras que si la hematuria tuviera su origen en parénquima renal, podría observarse una morfología variable, predominando los hematíes con irregularidades en su contorno. Esta observación reflejaría los cambios sufridos por los hematies dentro del túbulo renal, que no se comprobarían en las hematurias con origen en las vías urinarias.

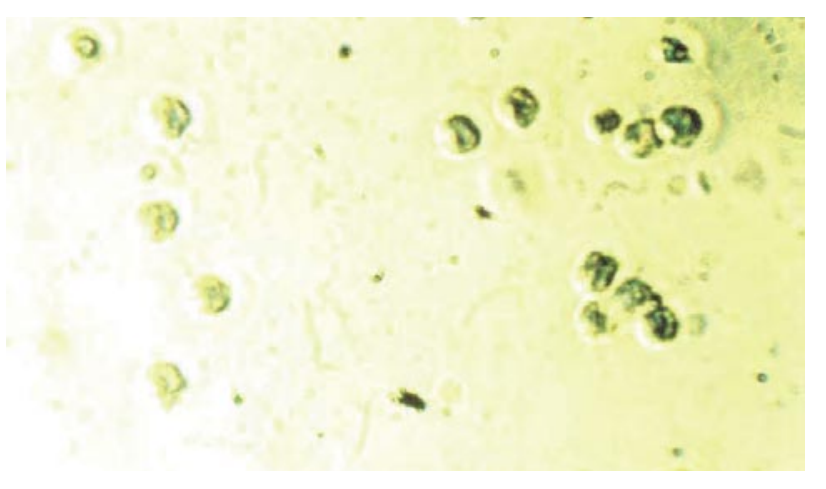

FIGURA 1. Leucocituria de mediana intensidad. Microscopía de contraste de fases.

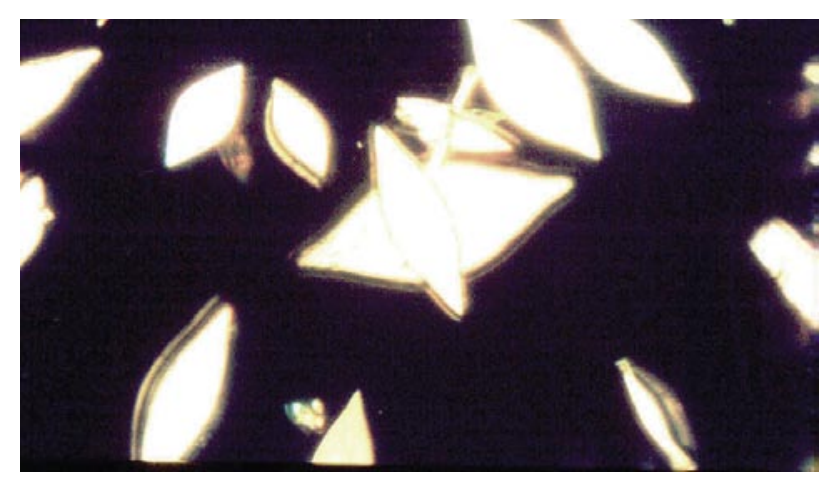

FIGURA 2. Cristales de ácido úrico. Microscopía de polarización. 


\section{Microscopía electrónica de barrido (SEM).}

El SEM crea imágenes aumentadas de tamaño, utilizando electrones, en vez de ondas de luz, como ocurre en el microscopio convencional de luz.

Un cañón emite un rayo de electrones de alta energía que viaja hacia abajo, iluminando la muestra, a través de una serie de lentes magnéticas, condensadores y antenas, diseñadas para dirigir los electrones a un punto, golpeando la muestra.

Los electrones secundarios quedan sueltos, en la superficie de la muestra. Un detector cuenta los electrones y envía las señales al amplificador.

La imagen final, se constituye con el número de electrones emitidos desde cada punto de la muestra, en blanco y negro y con carácter tridimensional.

Las muestras tienen que ser desecadas por diferentes métodos, y preparadas para conducir electrones.

La microscopía electrónica de barrido (SEM), ha sido utilizada en el estudio de los elementos formes de la orina, en diferentes ocasiones.

El SEM ha aportado muchos datos al conocimiento de los diversos cilindros urinarios, de tal forma que las imágenes de la matriz de los cilindros, nos han hecho superar algunas limitaciones en el estudio de los mismos.

Los cilindros hialinos podrían considerarse como el prototipo. Estos pueden presentar una superficie lisa (Figura 4), o fibrilar. Algunos autores

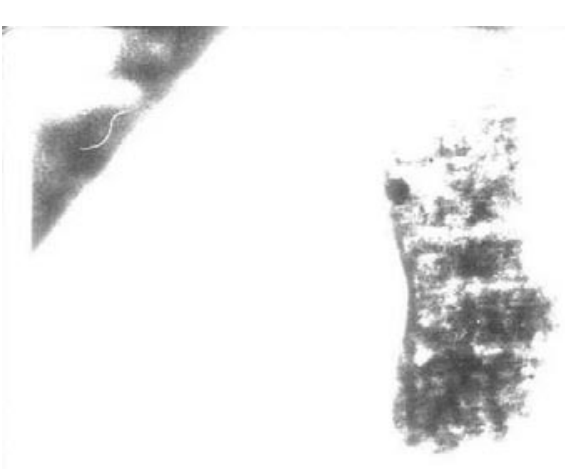

$980 R P 5$

FIGURA 3. Hematies isomorfos en orina. Microscopía electrónica de transmisión (TEM). justifican esta variedad, explicando el aspecto liso de algunos casos, por la existencia, asimismo, de un carácter fibrilar, pero con las fibras agrupadas tan estrechamente, que no permiten una resolución que consienta su correcta identificación.

El cilindro hialino, es el más frecuente de los cilindros urinarios y constituye la matriz para el resto de los cilindros (epiteliales, hemáticos, leucocitarios, y bacterianos), en la que se depositan los elementos correspondientes en su superficie.

\section{TEST REACTIVOS DE ORINA}

En general consisten en pruebas diagnósticas de fácil estandarización y fácil realización.

Las más frecuentemente utilizadas son las tiras reactivas multistix, que registran ph, proteínas, glucosa, sangre, pigmentos biliares, leucocitos, y nitritos.

El método de las tiras reactivas consiste en introducir, durante unos segundos, la zona reactiva de la tira en una muestra de orina recién emitida. Los resultados se leen a los 60 segundos comparando las alteraciones de los respectivos segmentos analíticos con una escala colorimétrica patrón.

La fiabilidad de las tiras es grande. La sensibilidad de estas tiras para la determinación de sangre oculta puede ser muy grande, pues microhematurias muy moderadas en las que se encuentran pocos hematies, en la observación microscópica del sedimento, dan claramente una reacción positiva. En caso de hemoglobinuria, lógicamente las tiras reactivas dan

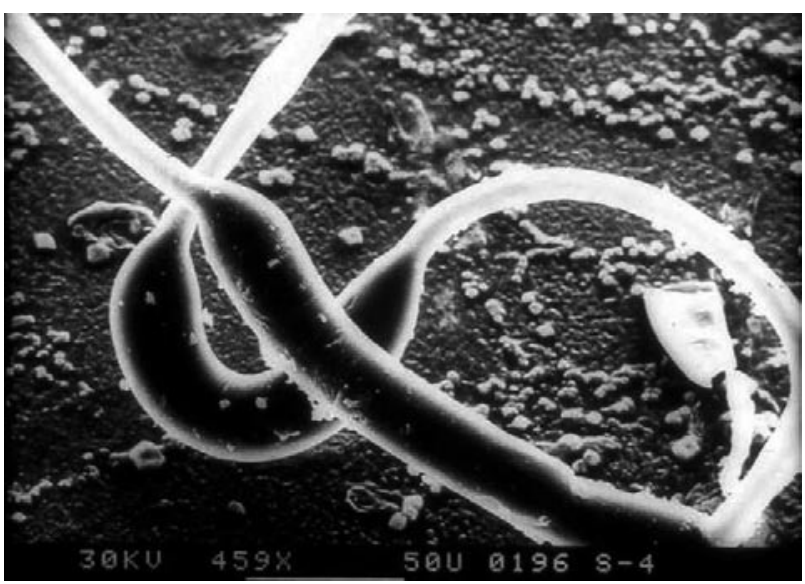

FIGURA 4. Cilindro hialino liso. Microscopía electrónica de barrido (SEM). 
positivo a sangre, debiendo acudir al estudio microscópico del sedimento, para realizar el diagnóstico diferencial con la hematuria.

Las tiras detectoras de leucocitos en orina, se basan en su reacción con las esterasas que se encuentran en los leucocitos. Son muy útiles, sobretodo cuando se utilizan con orinas recién emitidas, ya que los leucocitos de otra forma se lisan rápidamente.

Una reacción positiva al nitrito es aquella en la que aparece una coloración rosa después de introducir la tira en la orina. Esta reacción se basa en el cambio de color que produce el paso de nitrato urinario a nitrito, producido por los enzimas de los gérmenes que más frecuentemente se encuentran en la orina: Escherichia coli, Proteus, Klebsiella, Pseudomona aeruginosa. Detectan bacteriurias significativas, esto es, más de 100.000 col por cc de orina. Este rápido test podría tener, entre otras aplicaciones, evitar la realización de pruebas diagnósticas invasivas (cistoscopia, cistomanometría, biopsia prostática...), en pacientes en los que el test fuera positivo y retrasarlo para fechas cuando el mismo se halla negativizado, con el tratamiento antibiótico correspondiente.

Todos estos tests reactivos, por razones logísticas son muy utilizados en los grandes centros analíticos, como técnica de "screening", remitiendo los patológicos, o dudosos, al estudio microscópico (con contraste de fases) del sedimento urinario.

Asimismo, en estos centros, una alternativa al estudio convencional microscópico del sedimento centrifugado de orina, es la visualización de imágenes IRIS de los elementos formes, en muestras de orina (sin centrifugar), a semejanza de lo que se hace con las sangre en el estudio hematológico.

Estos tests reactivos con orina, obtenida de la micción, no se refieren a otros tipos, como sería la citología de orina (que exige tinción), citometría de flujo, BTA (para detección de cáncer vesical), y NMP22 (determinación de la proteína urinaria de la matriz nuclear en la detección del cáncer vesical), entre otros.

\section{2) EL LABORATORIO DEL URÓLOGO}

Es el título del libro donde el magistral Luis Cifuentes expuso y difundió sus conocimientos sobre el estudio científico de la orina, que le definieron e imprimieron carácter, allá por 1984.

Don Luis conocía perfectamente todas las técnicas descritas anteriormente, pero su mayor mérito fue elegir aquellas que por su sencillez, y operatividad, le aportan más datos al estudio de la patología del paciente. El sabía de las excelencias de la microscopía electrónica (por que las aplicó a otros campos de su actividad científica), pero por su complejidad, tamaño y objetivos a alcanzar escapaba a su estrategia.

Don Luis tenía muy claro lo que quería. El quería una metodología de estudio de la orina, junto a él, en los metros cuadrados de su consulta, y además este estudio debía realizarlo él mismo. Esto no era un capricho, tenía su explicación, ya que en primer lugar el estudio de la orina, formaba parte de la historia clínica del paciente, junto con la anamnesis, exploración física, tacto rectal..., que se realiza en la consulta; y segundo él insistió muchísimo para obtener unos datos fiables en el examen microscópico de la muestra, en la utilización de una muestra de orina recién emitida (en contra, de lo que sucede muchas veces en los grandes centros analíticos), y esto suponía que el enfermo realizara la micción en la propia consulta (si Mahoma no va a la montaña, la montaña viene a Mahoma).

La utilización de una orina recién eliminada, evitaría muchos de los artefactos y alteraciones que se presentan en una orina recogida durante 24 horas, o muestras de micción única, pero que han permanecido algún tiempo en laboratorio. Los leucocitos se lisan antes que los hematies. Una orina ácida y estéril retrasa esa lisis. La alcalinidad la favorece, así como una densidad baja de la orina.

En presencia de infección (sobretodo bacterias ureolíticas) se van alterando más rápidamente los leucocitos y hematies. El enfriamiento de la orina (una técnica muy recomendada para la conservación de la orina), favorece la nucleación y precipitación de cristales, por lo que poco o ningún valor tienen estos hallazgos en sedimento de una orina que haya permanecido a la temperatura de $4^{\circ} \mathrm{C}$.

Don Luis era un enamorado del estudio microscópico del sedimento centrifugado de la orina, con la microscopía de contraste de fases. Nadie más que él, ha adquirido tal capacidad de identificación de los elementos formes de la orina "en escala de grises" como reconocía él. Es maravillosa su descripción en la orina, de hematies, leucocitos, cristales, bacterias, histiocitos, cilindros y células uroteliales. Como comentaba él era como el estudio de una biopsia del tracto urinario.

Especial énfasis hace en lo referente a la identificación y estudio de las células uroteliales, fundamentalmente las neoplásicas. Son innumerables 


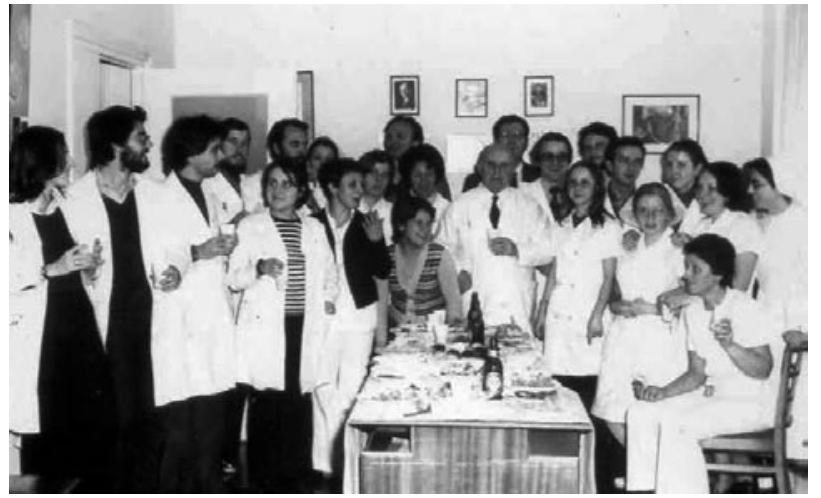

FIGURA 5. El Profesor Luis Cifuentes Delatte, rodeado de sus discípulos, en su Servicio de Urología, de la Fundación Jiménez Díaz, de Madrid en 1976.

los casos diagnosticados de neoformación urotelial (incluso carcinoma in situ), por el simple estudio microscópico del sedimento urinario, sin necesidad de tinción. Don Luis describía dichas células, como de tamaño grande, con gran desproporción citoplasmática, nucleolos gigantes, irregularidades de núcleo... En caso de sospecha, las refería al laboratorio de anatomía patológica para tinción de las mismas y confirmación del diagnóstico.

Algunos profesionales, no comparten la idea del laboratorio del urológo, del profesor Luis Cifuentes, y más hoy en día donde la medicina hospitalaria predomina. La entidad del laboratorio del urólogo, habría que entenderla, dentro del llamado "Office Urology", esto es, Consultorio de Urología. Esta entidad, que está muy difundida en USA y en la que Don Luis fue su más precoz y genuino representante en nuestro país, se refiere a que en un espacio pequeño, pero bien distribuido, el paciente entra por la puerta con unos síntomas urinarios, y sale de ella con un diagnóstico, sin necesidad de desplazarse e ir a más puertas. Esto exige que dicho gabinete posea la tecnología necesaria (que por otra parte no precisa de grandes superficies), para realizar actualmente: historia clínica, exploración física, cistoscopia, ecografía, flujometría..., y como Luis Cifuentes aconsejaba: el laboratorio del urológo: esta perspectiva del laboratorio del urólogo, contrasta con los laboratorios de las grandes superficies hospitalarias donde el estudio microscópico de la orina, está basado más que en la capacidad individual del profesional, en programas informáticos totalmente automatizados, que permiten la identificación de los diferentes elementos formes del sedimento urinario.

A la faceta, ya reconocida, de Don Luis, de insuperable endoscopista, y genial reseccionista, habría que añadir, en la terminología de Haber, de perfecto urinoscopista, entendiendo por ello no al clásico uroscopista (definido por el que practica el arte de examinar macroscópicamente la orina), sino aquel que somete la orina a un estudio científico y riguroso de la misma. De esta forma, Luis Cifuentes Delatte se constituiría en el prototipo de urinoscopista en urología (Figura 5).

\section{BIBLIOGRAFIA y LECTURAS RECOMENDADAS (*lectura de interés $y^{* *}$ lectura fundamental)}

1. SALINAS CASADO, J.: "La orina bajo el microscopio". Graficuatre, Valencia, 1984.

2. CIFUENTES DELATTE, L.: "El laboratorio del urólogo". Salvat, Barcelona, 1974. 